\title{
Lamé curve approximation for the assessment of the 3D temperature distribution in keyhole mode welding processes
}

Cite as: J. Laser Appl. 32, 022042 (2020); https://doi.org/10.2351/7.0000076

Submitted: 01 April 2020. Accepted: 01 April 2020. Published Online: 04 May 2020

Antoni Artinov (D), Victor Karkhin, Nasim Bakir, Xiangmeng Meng, Marcel Bachmann (D), Andrey Gumenyuk (D), and Michael Rethmeier (i)
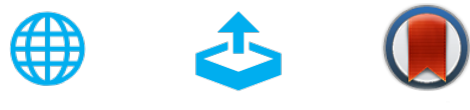

View Online

Export Citation

CrossMark

\section{ARTICLES YOU MAY BE INTERESTED IN}

Mathematical modeling of the geometrical differences between the weld end crater and the steady-state weld pool

Journal of Laser Applications 32, 022024 (2020); https://doi.org/10.2351/7.0000068

Influence of welding parameters on electromagnetic supported degassing of die-casted and wrought aluminum

Journal of Laser Applications 32, 022031 (2020); https://doi.org/10.2351/7.0000064

Theoretical study of influence of electromagnetic stirring on transport phenomena in wire feed laser beam welding

Journal of Laser Applications 32, 022026 (2020); https://doi.org/10.2351/7.0000069

\section{Scilight}




\title{
Lamé curve approximation for the assessment of the 3D temperature distribution in keyhole mode welding processes
}

Cite as: J. Laser Appl. 32, 022042 (2020); doi: 10.2351/7.0000076

Submitted: 1 April 2020 - Accepted: 1 April 2020 .

Published Online: 4 May 2020

Antoni Artinov, ${ }^{7}$ (D) Victor Karkhin, ${ }^{2}$ Nasim Bakir, ${ }^{7}$ Xiangmeng Meng, ${ }^{7}$ Marcel Bachmann, ${ }^{7}$

Andrey Gumenyuk, ${ }^{1}$ (D) and Michael Rethmeier ${ }^{1,2,3}$ (D)

\begin{abstract}
AFFILIATIONS
${ }^{1}$ BAM Federal Institute for Materials Research and Testing, Unter den Eichen 87, Berlin 12205, Germany

${ }^{2}$ Department of Welding and Laser Technologies, Peter the Great St. Petersburg Polytechnic University, Polytechnicheskaya str. 29,

195251 St. Petersburg, Russia

${ }^{3}$ Department of Joining Technology, Berlin Institute of Technology, 10623 Berlin, Germany
\end{abstract}

Note: This paper is part of the Special Collection: Proceedings of the International Congress of Applications of Lasers \&

Electro-Optics (ICALEO $\left.{ }^{\circledR} 2019\right)$.

\begin{abstract}
A novel approach for the reconstruction of an equivalent volumetric heat source from a known weld pool shape is proposed. It is based on previously obtained weld pool geometries from a steady-state thermo-fluid dynamics simulation. Hereby, the weld pool dimensions are obtained under consideration of the most crucial physical phenomena, such as phase transformations, thermo-capillary convection, natural convection, and temperature-dependent material properties. The algorithm provides a time and calibration efficient way for the reproduction of the weld pool shape by local Lamé curves. By adjusting their parameters, the identification of the finite elements located within the weld pool is enabled. The heat input due to the equivalent heat source is assured by replacing the detected nodes' temperature by the melting temperature. The model offers variable parameters making it flexible and adaptable for a wide range of workpiece thicknesses and materials and allows for the investigation of transient thermal effects, e.g., the cooling stage of the workpiece. The calculation times remain acceptably short especially when compared to a fully coupled process simulation. The computational results are in good agreement with performed complete-penetration laser beam welding experiments.
\end{abstract}

Key words: Lamé curves approximation, equivalent heat source, thermal cycles, numerical modeling, keyhole mode welding

Published under license by Laser Institute of America. https://doi.org/10.2351/7.0000076

\section{INTRODUCTION}

The joining of thick parts is strongly linked to the so-called keyhole phenomena. In keyhole mode welding techniques, such as laser beam, electron beam, and plasma jet, an intense heat is introduced locally, creating a narrow and deep vapor-filled cavity, which transfers the absorbed energy inside the workpiece. Thus, the material around the keyhole is liquidized, making the joining of thick workpieces possible. $^{1-3}$

Recently, high-power solid-state lasers with a maximal power of up to $100 \mathrm{~kW}$ became available, enabling an increase in the specimen thickness welded by a single pass up to $50 \mathrm{~mm} .{ }^{4-6}$ The high degree of focusability in laser beam welding in comparison to conventional multipass welding processes, such as gas metal arc and submerged arc welding, results in several advantages of a high importance for the quality of the welding process, such as:

- precise insertion of energy,

- low heat loading of the workpiece,

- reduced distortion after cooling,

- high processing speed,

- automation possibilities,

- no need for vacuum, etc. 
This leads to a steady growth of the current and potential application range of the laser beam welding process, ${ }^{7,8}$ which can be found in the automobile and aerospace industries as well as in the heavy section welding, e.g., shipbuilding and oil and gas industry. ${ }^{1,7,9,10}$

With the increasing use of keyhole mode welding technologies, it becomes highly relevant to investigate the underlying physical phenomena, especially in order to prevent defects in the material, such as solidification cracking and porosity. ${ }^{11-13}$ The high temperatures emerging during the welding process cause thermal expansion, microstructural changes, and alter the mechanical properties of the material, ${ }^{9,14}$ thus being responsible for residual stresses and distortion. ${ }^{15,16}$ Knowing the main cause and aiming the defect prevention, it is essential to predict the local thermal behavior of the part. $^{17,18}$

However, in the formulation of the heat conduction problem, the way the welding conditions are taken into account represents a main challenge and a critical point concerning the accuracy and the quality of the computation. In general, simple measurements can provide the amount of the total power $q_{\text {gross }}$ produced by the welding source, but the effective (net) power $q_{\text {eff }}$ (absorbed energy) and its distribution on the workpiece surface or within the keyhole are poorly known. In order to provide these missing data, a multiphysics simulation including, simultaneously the heat source, the metal vapor, the deformed heat source-liquid interface, the weld pool, and the solid, needs to be performed. Such a multi-scale model will need to account for a number of different physical effects, such as radiation, vaporization, laser reflections, thermo-capillary and natural convection, vapor induced shear stresses, phase transformations, etc., making it highly nonlinear and strongly coupled and hence limited through computational intensity. ${ }^{19-21}$

Nowadays, there are two methods of considering the welding conditions, which have proved their validity: (a) through a concentrated or distributed energy input or (b) by prescribing solidus temperature to the outer contour of the weld pool shape.

Usually, the first approach is preferred because of its lower computational requirements and the possibility of calibration. In this approach, the welding source is idealized and represented by a heat source model. One of the first heat source models in welding, the moving point heat source, was presented by Rosenthal in 1946. ${ }^{22}$ However, the solution of this problem was found much earlier and can be followed back to $1904 .^{23}$ Similar solutions were also presented in Refs. 24-26. Furthermore, the heat source modeling was expanded, and the simple point heat source was followed by several heat source models, such as the line heat source, the disk heat source model with a Gaussian surface flux distribution, ${ }^{27}$ and the volumetric heat source with a double ellipsoidal power density distribution. $^{17,28}$

Nevertheless, the calibration of the amount of net power and the corresponding distribution remains uncertain and slow. Fortunately, the second approach provides a reasonable solution, giving a very accurate description of the net power without the need for additional calibration. The main idea is based on the concept of the so-called equivalent heat source (EHS). ${ }^{29,30}$ The EHS is described by the solidliquid interface, which itself is defined by the solidus isotherm $T_{s}$. Hence, all the relevant information (heat source parameters) for the resulting temperature field outside the molten pool are included, and there is no need for further calibration. ${ }^{29,31}$ The temperature field around the weld pool is found by specifying the geometry of its solidus interface in time and space. The needed weld pool shape can be obtained from a thermo-fluid dynamical simulation or an experimental procedure. This method was first applied to the solution of two-dimensional problems in $1969 .{ }^{27}$ It was implemented by the finite difference method (FDM) and later on used in Ref. 29 for the investigation of residual stresses and distortion of welded joints in AlMgSi alloys. More recently, this approach was applied to the threedimensional heat source problem of complete-penetration high power laser beam welding of thick metal plates by using the finite element method (FEM). ${ }^{30}$

Overall, the consideration of the welding conditions remains a challenge for the numerical simulation of the heat conduction problem. The use of heat source models requires high calibration effort with relatively low accuracy. On the other hand, the consideration of a coupled heat source-weld pool-workpiece multiscale problem is visionary due to the high computational requirements. The option of decoupling this multiphysics problem, allowing for a successive approach of the heat conduction problem, and thus providing high accuracy results by reasonable computational intensity represents a very promising method. Hence, new techniques improving this methodological task of decoupling have to be developed.

The aim of the present study is to develop an efficient numerical framework in order to reduce the computational time to a feasible level with a reasonable exactness of the computed temperature field and thermal cycles. The proposed technique is based on the concept of the volumetric equivalent heat source and exemplarily applied to a multiscale simulation of high-power laser beam welding of $15 \mathrm{~mm}$ thick low-alloyed steel plates S355.

\section{THEORY}

The developed numerical algorithm proposed in this work is based on the concept of the equivalent heat source $27,29,30$ and includes three main steps:

(1) solution of the thermo-fluid dynamics problem for the CFD domain on a local level, see Fig. 1,

(2) reconstruction of the weld pool interface by suitable continuous approximation functions, and

(3) solution of the heat conduction problem for the entire workpiece.

These steps are further described and discussed below.

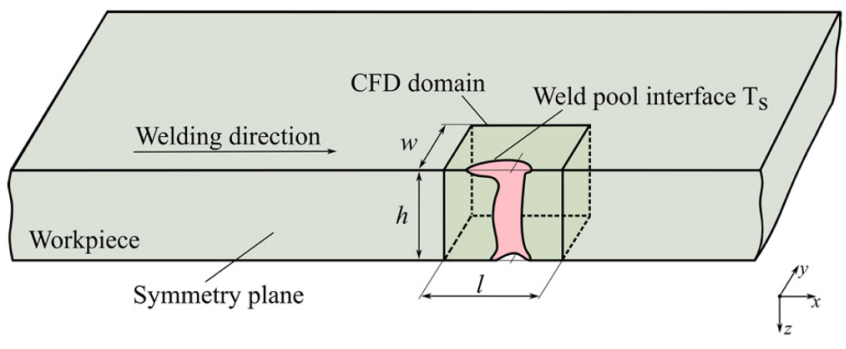

FIG. 1. Moving isothermal weld pool interface in a plate. Only one half of the plate is shown. 
The formulation and the solution of the thermo-fluid dynamics problem are presented in detail in Ref. 30 . The model considers the main and most important physical phenomena for the weld pool formation, namely, thermo-capillary convection, natural convection, phase transformations, and temperature-dependent material properties up to evaporation temperature.

The approximation of the numerically calculated or experimentally obtained molten pool geometry is realized with the so-called Lamé curves. For this, the liquid-solid interface should be available either as a continuous shape or as discretized data points. The procedure starts by dividing the data into $K$ levels along the height $h$ (z-direction) of the weld pool, see Fig. 2. The data points in each level are approximated by two Lamé curves, one approximating the front and one the rear part of the molten pool. Note that the maximum width $b$ of the two approximating curves should be equal for each level $k$. The corresponding generalized Lamé-curve equations are given as follows:

$$
\left(\frac{\left|x-x_{c}\right|}{a_{r}(z)}\right)^{m_{r}(z)}+\left(\frac{|y|}{b(z)}\right)^{n_{r}(z)}=1
$$

for $x<x_{c}$ with $m_{r}, n_{r}>1$ and

$$
\left(\frac{\left|x-x_{c}\right|}{a_{f}(z)}\right)^{m_{f}(z)}+\left(\frac{|y|}{b(z)}\right)^{n_{f}(z)}=1
$$

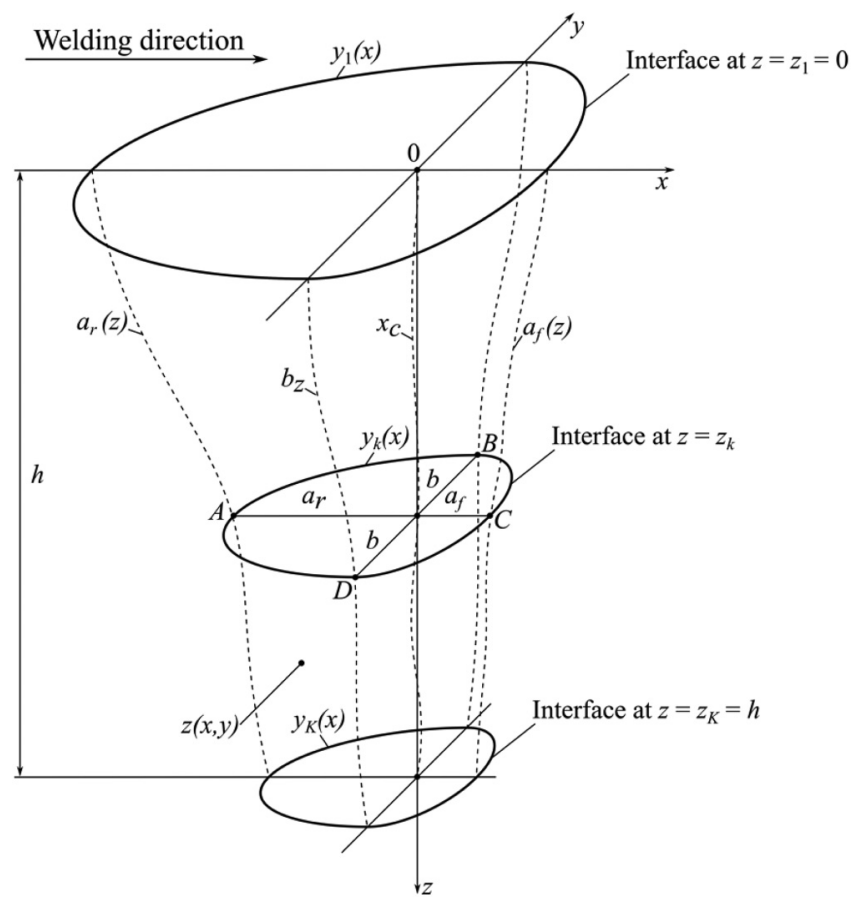

FIG. 2. Approximation of the weld pool interface $T=T_{s}$ as a surface $z(x, y)$. for $x \geq x_{c}$ with $m_{f} n_{f}>1$, where $x_{c}$ is the center of the Lamé curves, $m_{r, f}(z)$ and $n_{r, f}(z)$ are the shape parameters of the curves, $\mathrm{a}_{r, f}(z)$ are the semimajor axes (approximated length of the front and rear parts of the weld pool) and $b(z)$ is the semiminor axis (approximated width of the weld pool).

Additionally, in order to guarantee symmetry and a smooth shape, the two curves are forced to be continuous. Thus, the following conditions should be met:

$$
\begin{gathered}
\frac{d y_{l}}{d x}=0 \quad \text { at } \mathrm{y}= \pm b \quad(\text { points } B \text { and } D), \\
\frac{d y_{l}}{d x}=\infty \quad \text { at } x=-a_{r} \quad(\text { points } A), x=a_{f}(\text { points } C) .
\end{gathered}
$$

Theoretically, to obtain all eight parameters $\left(a_{r}, a_{f}, x_{c}, b, m_{r}, n_{r}, m_{f}, n_{f}\right)$, at least eight data points are required. However, the accuracy of the approximation is improved by taking more data points. For the fitting procedure of the function, the least square method is applied, to optimally reproduce the $2 \mathrm{D}$ contour for each depth $z_{k}=$ const. The objective function to be minimized is defined as follows:

$$
\begin{aligned}
& F\left(a_{i}(z), b(z), x_{c}(z), m_{i}(z), n_{i}(z)\right) \\
& \quad=\frac{1}{L_{\text {total }}} \times \sum_{l=1}^{L_{\text {total }}} w_{l}\left(y_{l}-b\left(1-\left(\frac{\left|x_{l}-x_{c}\right|}{a_{i}}\right)^{m_{i}}\right)^{\frac{1}{n_{i}}}\right)^{2} \rightarrow \min
\end{aligned}
$$

for $i=f, r$. The running index $i$ is used to switch between the front and the rear parts of the weld pool. Here, $y_{l}$ is a given data point at a certain depth $z_{k}=$ const., with $L$ being the total number of data points in this plane and $w_{l}$ is a weighting factor. The minimal error is found by taking the derivative of Eq. (5) with respect to each unknown variable as exemplarily shown in Eq. (6) for the parameter $a_{i}$

$$
\begin{aligned}
\frac{\partial F}{\partial a_{i}}= & -2 \frac{w_{l} b m_{i}}{L_{\text {total }} n_{i} a_{i}^{m_{i}+1}} \sum_{l=1}^{L_{\text {total }}}\left|x_{l}-x_{c}\right|^{m_{i}} \\
& \times\left[y_{l}-b\left(1-\frac{\left|x_{l}-x_{c}\right|^{m_{i}}}{a_{i}^{m_{i}}}\right)^{\frac{1}{n_{i}}}\right]\left(1-\frac{\left|x_{l}-x_{c}\right|^{m_{i}}}{a_{i}^{m_{i}}}\right)^{\frac{1-n_{i}}{n_{i}}} \stackrel{!}{=} 0 .
\end{aligned}
$$

Taking the derivative of Eq. (5) with respect to the remaining variables produces a nonlinear system of equations, which is solved for the required parameters. The procedure provides the parameters for one certain plane and has to be repeated $K$ times for each single plane. The missing values between the planes can then be obtained by interpolation between the known values. In the case, that an analytical expression is preferred or needed, a single function dependent on the $z$-coordinate can be obtained by fitting the data by a polynomial of the form

$$
f\left(z_{k}\right)=c_{0}+c_{1} z_{k}+c_{2} z_{k}^{2}+\cdots+c_{j} z^{j},
$$

with $j \leq K-1$. If using the polynomial approach, the least square 
method can be applied again to minimize the deviation $W$ in Eq. (7),

$$
W=\sum_{k=1}^{K} w_{k}\left(f\left(z_{k}\right)-\left(c_{0}+c_{1} z_{k}+c_{2} z_{k}^{2}+\cdots+c_{j} z^{j}\right)\right)^{2} .
$$

Making use of the determined polynomial functions for all eight parameters and of Eqs. (1) and (2), the 3D weld pool contour can be described and hence a volumetric equivalent heat source can be created.

The volumetric EHS is subsequently used to calculate the temperature field by detecting the finite elements located within the weld pool, and replacing their node's temperature by the melting temperature. The transient temperature distribution of the workpiece is calculated by solving the $3 \mathrm{D}$ heat conduction equation with respect to the corresponding boundary conditions,

$$
\frac{\partial T}{\partial t}=a \nabla^{2} T
$$

where $a$ is the thermal diffusivity. In order to improve the solving time, the computational domains exploit a symmetry condition so that only one half of the real part has to be modeled. Hence, the normal heat flux through the symmetry plane (see Fig. 1) is set to zero,

$$
-n \cdot(-\lambda \nabla T)=0 .
$$

The boundary conditions used in the thermo-fluid dynamics simulation (CFD) can be taken from Ref. 30. Heat losses in the heat conduction simulation of the entire workpiece appear mostly through the upper and lower surfaces. Since their amount is negligibly small compared to the heat introduced by the EHS, ${ }^{30}$ Eq. (10) is applied again. For the sake of simplicity, the temperature of the remaining outer surfaces far away from the weld pool is either set to be equal to the initial temperature $T_{0}$ or considered adiabatic, depending on the size of the workpiece and the field of action of the heat source.

\section{EXAMPLE}

The proposed numerical framework is applied to a $15 \mathrm{~mm}$ thick steel plate made of the low-alloyed ferritic steel S355 (0.17\% $\mathrm{C}$ and $1.4 \% \mathrm{Mn}$ ). It is the aim to calculate the temperature field during complete-penetration laser beam welding in order to obtain the time-temperature curves at specific locations in the workpiece. The processing time is $5 \mathrm{~s}$ at a welding speed of $33 \mathrm{~mm} \mathrm{~s}^{-1}$ and a laser beam power of $18 \mathrm{~kW}$. The thermo-physical material properties are shown in Fig. 3. ${ }^{30,32}$

An additional study of the influence of the temperature dependency of the material properties on the resulting temperature field is performed. Since there are no significant differences between the obtained temperature distributions, the mean integral values for $\lambda=600 \frac{\mathrm{W}}{\mathrm{m} \mathrm{K}}, c=40 \frac{\mathrm{J}}{\mathrm{kg} \mathrm{K}}$, and $\rho=7650 \frac{\mathrm{kg}}{\mathrm{m}^{3}}$ are used for the investigation of the solid state heat conduction model in order to optimize the computational time.

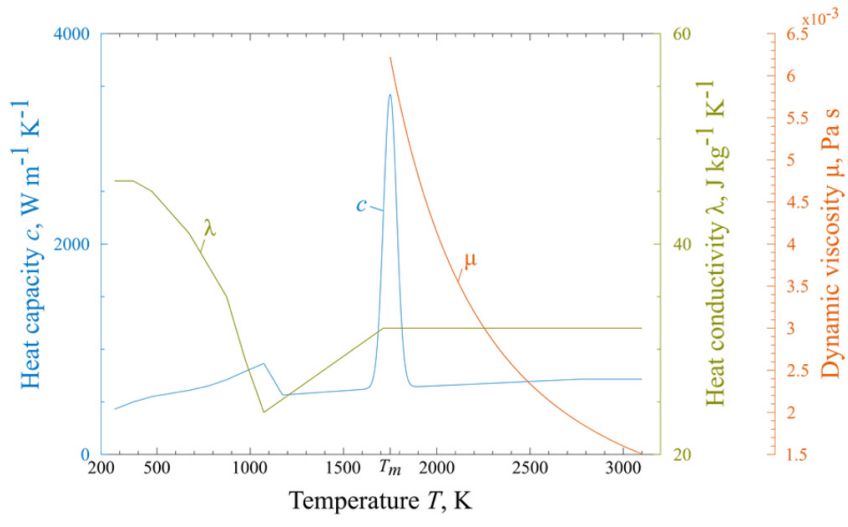

FIG. 3. Temperature-dependent material properties of the low-alloyed steel S355 used in the CFD simulation.

\section{THERMO-FLUID DYNAMICS COMPUTATION (CFD)}

The weld pool geometry used in this example is a result of a complete-penetration thermo-fluid dynamics simulation performed by the authors. The mathematical formulation of the CFD problem and all assumptions made are used and presented in similar studies. ${ }^{30,32,33}$ The model makes use of the Eulerian approach and considers the workpiece as infinitely long and moving relative to the origin of the Cartesian coordinate system, which coincides with the origin of the heat source. The heat source itself is modeled by a fixed keyhole geometry based on the assumption that the recoil pressure in the keyhole is perfectly balanced by the surface tension forces. In that configuration, the keyhole radii are a kind of free model parameter to obtain good agreement with the experimental observations. Since the keyhole diameter is much smaller than the width of the weld pool, the influence of the keyhole shape on the flow field is relatively small (low Peclet number), whereas the heat input and the resulting amount of molten material depend on the keyhole radii. Furthermore, the main physical phenomena, such as thermo-capillary convection, natural convection, phase transformations, and temperature-dependent material properties up to the evaporation temperature, are considered. The computation domain of the steady-state CFD simulation has the dimensions of $70 \times 10 \times 15 \mathrm{~mm}^{3}$. For its discretization, a mesh with about $1.46 \times 10^{6}$ tetrahedral elements and a minimum element size of $0.1 \mathrm{~mm}$ in the vicinity of the keyhole and the region influenced by the thermo-capillary force is applied. Further details about assumptions, geometry, mesh, and numerical parameters can be found in Ref. 30.

\section{RECONSTRUCTION OF THE 3D WELD POOL GEOMETRY BY LOCAL LAMÉ CURVES}

For the complete approximation and description of the modeled three-dimensional weld pool, local Lamé curves are used. In this example, the $3 \mathrm{D}$ weld pool shape is available from the CFD calculation as a set of data points. This is divided into 40 planes with a variable spacing along the $z$-coordinate to obtain good 
approximations of the interface even in the more complex shaped areas influenced by the Marangoni convection. Every 2D contour in each plane is sufficiently approximated by Eqs. (1) and (2), having eight parameters to be determined. In Fig. 4, the approximations of the weld pool at three different heights $z_{k}$, the top surface
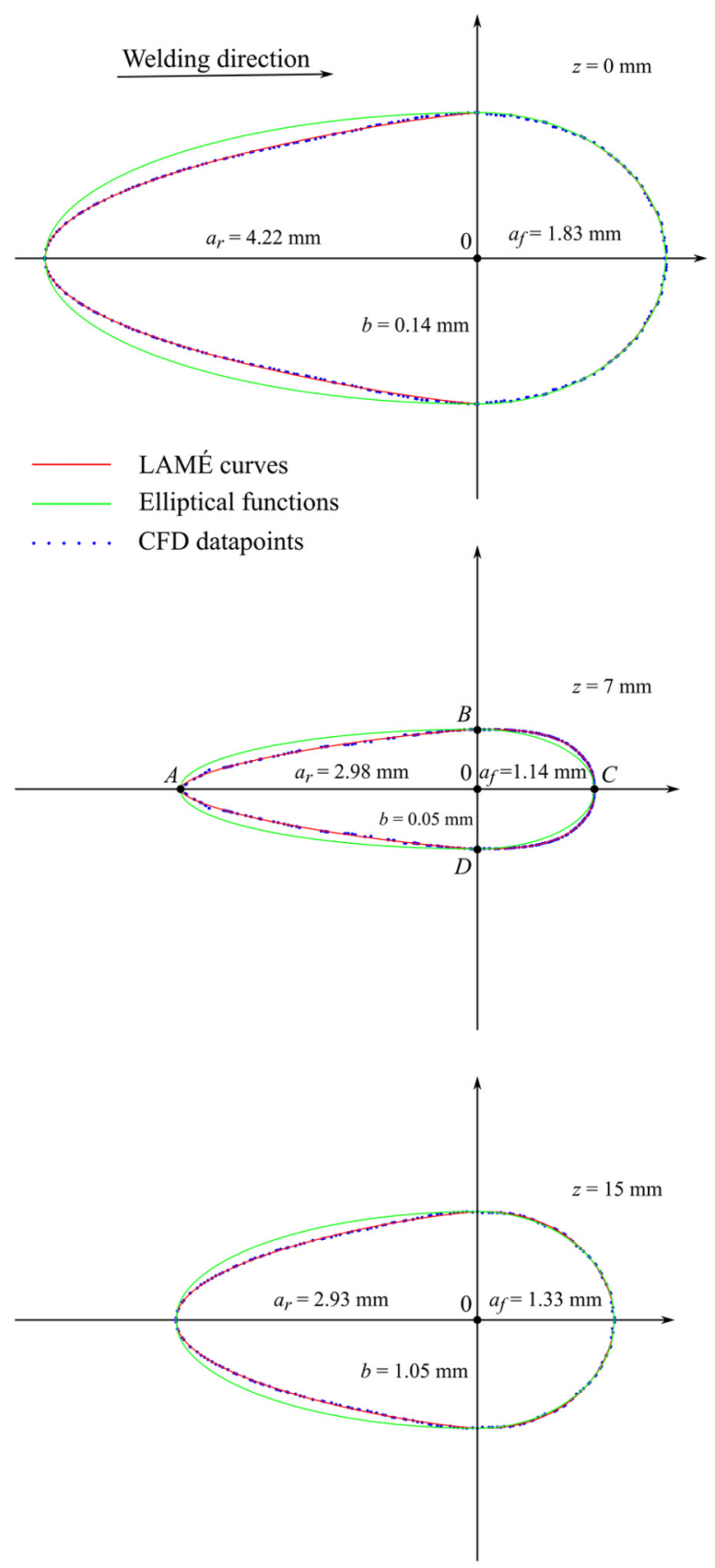

FIG. 4. Approximation of the CFD data points ${ }^{30}$ by elliptical functions and Lamé curves. plane at $z=0 \mathrm{~mm}$, a plane within the weld pool at $z=7 \mathrm{~mm}$, and the bottom surface plane at $z=15 \mathrm{~mm}$ are shown. Since the weld pool shape is assumed to have an elliptic form in most of the 2D cases, an additional approximation of the contours in the three planes by considering the shape parameters $m_{r, f}(z)=n_{r, f}(z)=2$ and hence turning the generalized Lamé curves into ellipses is added.

As it can be seen in Fig. 4, the accuracy of the approximation of the weld pool contour by an elliptical function is much lower than that of the Lamé curves.

\section{COMPUTATION OF THE 3D STEADY-STATE TEMPERATURE FIELD}

The calculated shape parameters of the weld pool interface are subsequently used by the computation of the temperature cycle. The algorithm detects the nodes fulfilling Eqs. (1) and (2) and replaces their temperature by the melting temperature. Hence, the heat input due to the volumetric equivalent heat source is assured. Its movement in time is realized by shifting the $x$-values of the nodes and thus the EHS with the processing speed in the welding direction. Accordingly, to this movement, Eqs. (1) and (2) are modified and shifted by the value of $-v t$ during the simulation. Such an approach benefits from the fixed geometry and mesh and leads to reduced computational time and intensity.

In Figs. 5(a) and 5(b), the geometry of the EHS reproduced by the proposed algorithm is shown. This results from the calculated $3 \mathrm{D}$ temperature field and is compared to the initial weld pool shapes from the CFD simulation, highlighted with white lines. Figure 5(a) shows the comparison in the longitudinal direction in the symmetry plane, while in Fig. 5(b), the $2 \mathrm{D}$ contour at $z_{1}=0 \mathrm{~mm}$ is shown. The white lines represent the solidus isotherm $T_{s}$ from the CFD model, whereas the colored images show the temperature field, modeled by the Lamé-curve equations.

As it can be seen from Fig. 5, the weld pool shape, typically strongly influenced in the upper and lower regions by the Marangoni convection, ${ }^{30}$ is well depicted. Note that the weld pool shape extracted from the CFD simulation (white lines) has a slightly larger size, which is mainly dependent on the discretization (mesh size) and the amount of released latent heat.

In order to verify the initial weld pool shape used in the proposed numerical framework as well as to validate the calculated temperature field, welding experiments are performed.

The accuracy calculated with the CFD model's weld pool shape and dimensions, later on used for the reconstruction of the EHS by local Lamé curves, is verified by metallographic cross sections. Additionally, the weld pool lengths on the upper and lower surfaces in the model (approximately 6.3 and $4.4 \mathrm{~mm}$, respectively) are compared to the lengths of the weld end crater from the experiments (approximately 6.9 and $4.9 \mathrm{~mm}$, respectively). When doing so, it should be borne in mind that the geometrical dimensions of the weld end crater are slightly bigger than those of the steady-state weld pool due to overheating effects of the molten material once the laser is shut down, leading to further melting of the base material. Hence, the obtained numerical dimensions agree very well with the measurements. ${ }^{30}$

For the validation of the thermal behavior, temperature measurements at specific locations on the top and bottom surfaces of 
a)

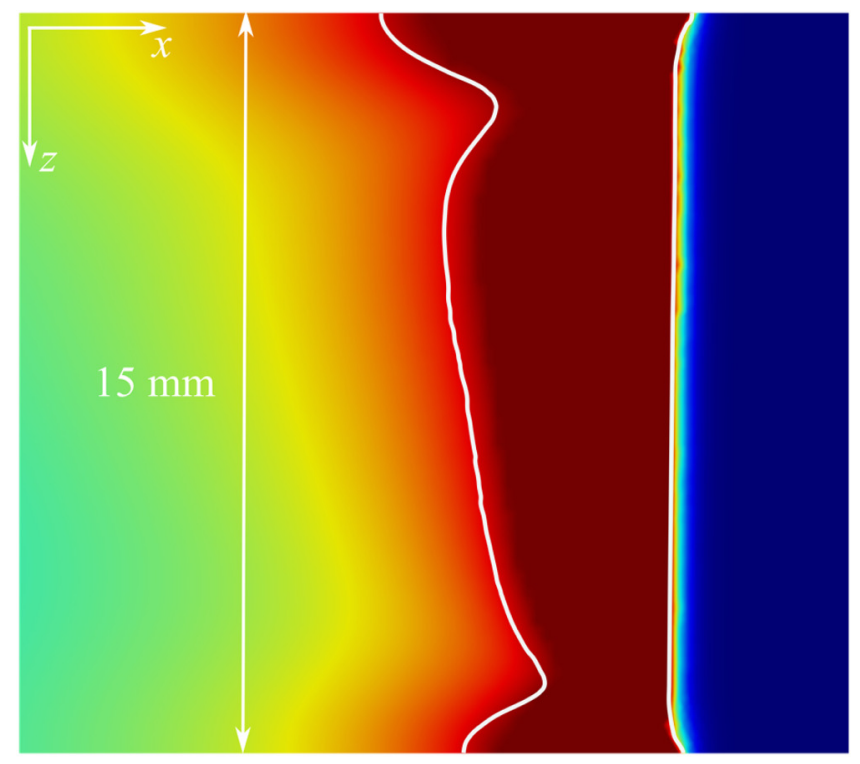

$$
\nabla 293
$$

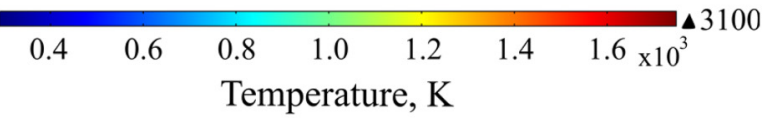

b)

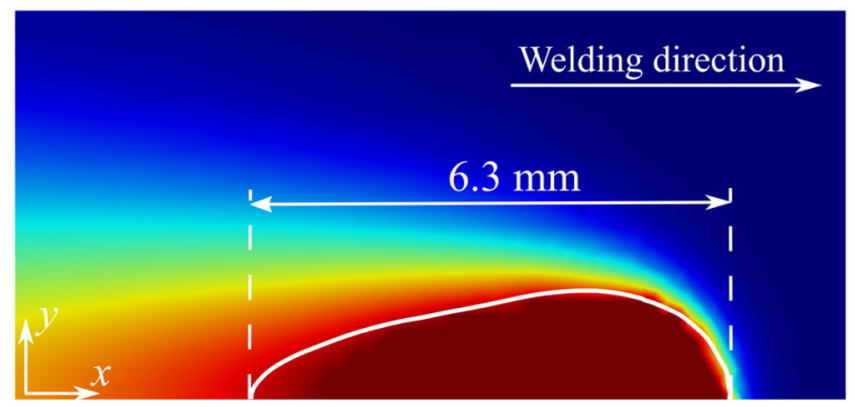

FIG. 5. Calculated temperature field (a) in the symmetry plane and (b) at the upper surface $\left(z_{1}=0\right)$. White lines represent the initial weld pool interface from the steady-state CFD simulation. ${ }^{30}$

the plate are performed. The used thermocouples are of type $\mathrm{K}$ with a diameter of 0.1 and $0.25 \mathrm{~mm}$. These were located at different distances from the weld center line, between 1 and $2 \mathrm{~mm}$. More detailed description of the experimental procedure can be found in Ref. 30.

In Fig. 6, the comparison of the numerically calculated and experimentally measured thermal cycles is shown. As it can be seen from the curves, the proposed reconstruction algorithm for the EHS captures well the thermal behavior of the part. The maximum temperature in all measurement positions is accurately predicted by the model. a)

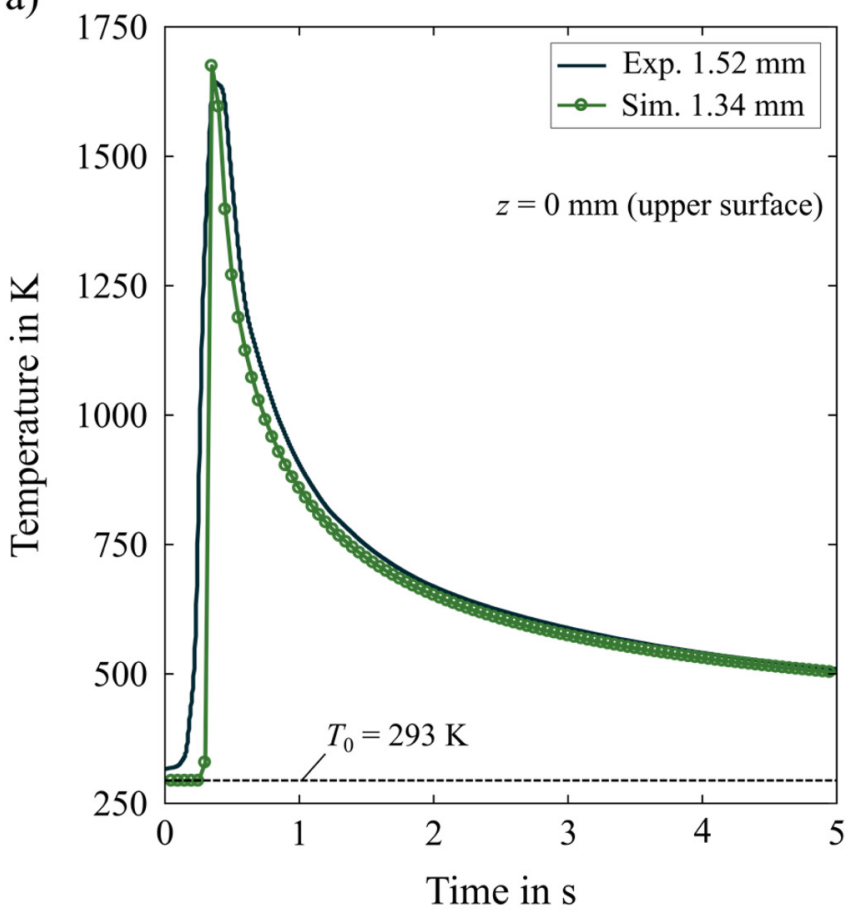

b)

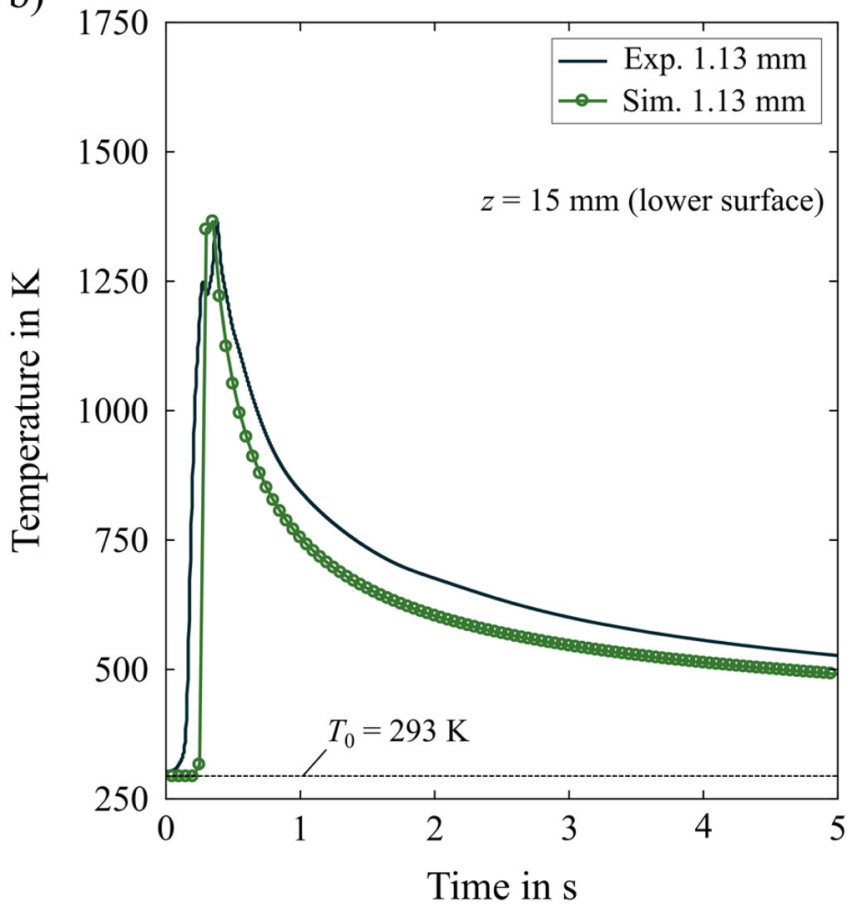

FIG. 6. Comparison of the numerically computed and experimentally obtained thermal cycles at different distances from the symmetry plane (a) on the upper surface $(z=0 \mathrm{~mm})$ and $(b)$ on the lower surface $(z=15 \mathrm{~mm})$ of the plate. 
Nevertheless, there are some minor differences between the calculated and the measured time-temperature curves on the lower surface of the workpiece during the cooling stage of the process. However, these differences are still small enough, having their maximum in the temperature range below $500{ }^{\circ} \mathrm{C}$. Thus, the deviation does not have an impact on the predictions made by the model, regarding transient and residual stresses, microstructural changes, etc. The main cause of this deviation is the lower energy input in the lower part of the plate due to the smaller keyhole cross section. $^{30}$

\section{CONCLUSIONS}

In this work, a novel numerical framework for the reconstruction of an equivalent volumetric heat source and its application by the computation of the three-dimensional thermal cycle is developed. The proposed algorithm accounts for the welding conditions as well as for the main physical phenomena relevant for the heat and mass transfer, such as thermo-capillary convection, natural convection, phase transformations, and temperature dependency of the material properties. The weld pool interface is approximated by a set of weld pool contours at different depths of the plate. Each contour is described by two local Lamé curves and connected with its neighbors by continuous functions. This approach results in plausible reconstruction of any real weld pool geometry.

The procedure allows for the investigation of transient thermal effects in the weld specimen, e.g., the cooling stage of the workpiece and reduces the computational time and the calibration effort by an order of magnitude especially when compared to a fully coupled process simulation.

The numerically calculated and experimentally obtained thermal cycles in the heat affected zone are in close agreement.

The presented method has great potential to be used for structural analysis, creating a fast and simple way to link thermal and structural simulations and thus providing an important step for the further investigation of physical phenomena and problems caused by the keyhole mode welding processes.

\section{ACKNOWLEDGMENTS}

Financial funding by the Deutsche Forschungs-gemeinschaft (DFG, German Research Foundation, Project No. 411393804) is gratefully acknowledged. This work was supported by the Research Association for Steel Application (FOSTA), the Federation of Industrial Research Associations (AiF) and the German Federal Ministry for Economic Affairs and Energy, (BMWi Bundesministerium für Wirtschaft und Energie) (Project No. 19582, "Investigation of the influence of the restraint conditions on hot cracking in laser and laser-hybrid welding of thick structure steels").

\section{REFERENCES}

${ }^{1}$ M. Bachmann, A. Gumenyuk, and M. Rethmeier, "Welding with high-power lasers: Trends and developments," Phys. Proc. 83, 15-25 (2016).

${ }^{\mathbf{2}}$ V. A. Karkhin, Thermal Processes in Welding (Springer, Singapore, 2019), p. 515.

${ }^{3}$ V. A. Karkhin, Thermal Processes in Welding, 2nd ed. (Polytechnic University Publishing, St. Petersburg, 2015), p. 572
${ }^{4}$ L. Quintino, A. Costa, R. Miranda, D. Yapp, V. Kumar, and C. J. Kong, "Welding with high power fiber lasers-A preliminary study," Mater. Des. 28, 1231-1237 (2007).

${ }^{\mathbf{5}}$ S. E. Nielsen, "High power laser hybrid welding-Challenges and perspectives," Phys. Procedia 78, 24-34 (2015).

${ }^{6}$ X. Zhang, E. Ashida, S. Tarasawa, Y. Anma, M. Okada, S. Katayama, and M. Mizutani, "Welding of thick stainless steel plates up to $50 \mathrm{~mm}$ with high brightness lasers," J. Laser Appl. 23, 022002 (2011).

${ }^{7}$ M. Kocak, J. Dos Santos, and S. Riekehr, "Trends in laser beam welding technology and fracture assessment of weld joints," Sci. Technol. Weld. Join. 6, 347-350 (2001).

${ }^{8}$ V. V. Avilov, A. Gumenyuk, M. Lammers, and M. Rethmeier, "PA position full penetration high power laser beam welding of up to $30 \mathrm{~mm}$ thick $\mathrm{AlMg}_{3}$ plates using electromagnetic weld pool support," Sci. Technol. Weld. Join. 17, 128-133 (2012).

${ }^{9}$ M. Sokolov, A. Salminen, M. Kuznetsov, and I. Tsibulskiy, "Laser welding and weld hardness analysis of thick section S355 structural steel," Mater. Des. 32, 5127-5131 (2011).

${ }^{10}$ E. Schubert, M. Klassen, I. Zerner, C. Walz, and G. Sepold, "Light-weight structures produced by laser beam joining for future applications in automobile and aerospace industry," J. Mater. Process. Technol. 115, 2-8 (2001).

${ }^{11}$ S. Katayama, "Defect formation mechanisms and preventive procedures in laser welding," in Handbook of Laser Welding Technologies (Woodhead Publishing, Cambridge, UK, 2013), pp. 332-373.

${ }^{12} \mathrm{~N}$. Bakir, A. Gumenyuk, and M. Rethmeier, "Investigation of solidification cracking susceptibility during laser beam welding using an in-situ observation technique," Sci. Technol. Weld. Join. 23, 234-240 (2018).

${ }^{13}$ V. P. Kujanpää, "Weld defects in austenitic stainless steel sheets-effect of welding parameters," Weld. J. 62, 45-52 (1983).

${ }^{14}$ G. A. Moraitis and G. N. Labeas, "Residual stress and distortion calculation of laser beam welding for aluminum lap joints,” J. Mater. Process. Technol. 198, 260-269 (2008).

${ }^{15} \mathrm{M}$. O. Gebhardt, A. Gumenyuk, and M. Rethmeier, "Numerical analysis of hot cracking in laser-hybrid welded tubes," Adv. Mater. Sci. Eng. 2013, 520786 (2013).

${ }^{16}$ M. O. Gebhardt, A. Gumenyuk, and M. Rethmeier, "Solidification cracking in laser GMA hybrid welding of thick-walled parts," Sci. Technol. Weld. Join. 19, 209-213 (2014).

17J. Goldak, A. Chakravarti, and M. Bibby, "A new finite element model for welding heat sources,” Metall. Trans. B 15, 299-305 (1984).

${ }^{18}$ A. Pittner, D. Weiss, C. Schwenk, and M. Rethmeier, "Methodology to improve applicability of welding simulation," Sci. Technol. Weld. Join. 13, 496-508 (2008).

${ }^{19}$ W. I. Cho, S. J. Na, C. Thomy, and F. Vollertsen, "Numerical simulation of molten pool dynamics in high power disk laser welding," J. Mater. Process. Technol. 212, 262-275 (2012).

${ }^{20}$ L. J. Zhang, J. X. Zhang, A. Gumenyuk, M. Rethmeier, and S. J. Na, "Numerical simulation of full penetration laser welding of thick steel plate with high power high brightness laser," J. Mater. Process. Technol. 214, 1710-1720 (2014).

${ }^{21}$ S. Pang, X. Chen, J. Zhou, X. Shao, and C. Wang, “3D transient multiphase model for keyhole, vapor plume, and weld pool dynamics in laser welding including the ambient pressure effect," Opt. Lasers Eng. 74, 47-58 (2015).

${ }^{22} \mathrm{D}$. Rosenthal, "The theory of moving sources of heat and its application of metal treatments," Trans. ASME 68, 849-866 (1946).

${ }^{23}$ H. A. Wilson, "On convection of heat," Proc. Cambridge Philos. Soc. 12, 406-423 (1904).

${ }^{\mathbf{2 4}} \mathrm{N}$. N. Rykalin, "Calculation of heat flow in welding," translated by Z. Paley and C. M. Adams, Jr., Contract N. UC-19-066-001-C3817 (1951).

${ }^{25}$ N. N. Rykalin, Die Wärmegrundlagen des Schweissvorganges (Verlag Technik, Berlin, 1952).

${ }^{26}$ N. N. Rykalin, Berechnung der Wärme-voränge beim Schweißen (VEB Verlag Technik, Berlin, 1958). 
${ }^{27} \mathrm{~V}$. Pavelic, "Experimental and computed temperature histories in gas tungsten arc welding of thin plates," Weld. J. Res. Suppl. 48, 296-305 (1969).

${ }^{28}$ J. R. Chukkan, M. Vasudevan, S. Muthukumaran, R. R. Kumar, and N. Chandrasekhar, "Simulation of laser butt welding of AISI 316L stainless steel sheet using various heat sources and experimental validation," J. Mater. Process. Technol. 219, 48-59 (2015).

${ }^{29} \mathrm{D}$. Radaj, H. Häuser, and S. Braun, "Numerische Simulation von Eigenspannungen und Verzug bei Schweißverbindungen aus AlMgSiLegierungen," Konstruktion 50, 31-37 (1998).

${ }^{30}$ A. Artinov, M. Bachmann, and M. Rethmeier, "Equivalent heat source approach in a 3D transient heat transfer simulation of full-penetration high power laser beam welding of thick metal plates," Int. J. Heat Mass Transfer 122, 1003-1013 (2018).

${ }^{31}$ R. P. Turner, C. Panwisawas, Y. Sovani, B. Perumal, R. M. Ward, H. C. Basoalto, and J. W. Brooks (2016) "Linking a CFD and FE analysis for welding simulations in Ti-6Al-4V," in 10th International Conference on Trends in Welding Research and 9th International Welding Symposium of Japan Welding Society (9WS), Tokyo, Japan, 11-14 October 2016 (American Welding Society, Miami, 2016), Vol. 1, pp. 960-963.

${ }^{32}$ N. Bakir, A. Artinov, A. Gumenyuk, M. Bachmann, and M. Rethmeier, "Numerical simulation on the origin of solidification cracking in laser welded thick-walled structures," Metals 8, 406 (2018).

${ }^{33}$ M. Bachmann, V. Avilov, A. Gumenyuk, and M. Rethmeier, "Numerical simulation of full-penetration laser beam welding of thick aluminium plates with inductive support," J. Phys. D Appl. Phys. 45, 035201 (2011).

\section{Meet the Authors}

Antoni Artinov, born in 1991 in Aytos (Bulgaria), received his M.Sc. in the field of Engineering Science from the Berlin Institute of Technology and his M.Sc. in Mechanical Engineering from the Tomsk Polytechnic University. Since 2016, he is working as a research assistant at the Federal Institute for Materials Research and Testing in Berlin, Germany, in the department "Welding Technology." Currently, he is working in the field of numerical simulations in laser beam welding processes.

Professor Dr.-Ing. Victor Karkhin works at the Department of Welding and Laser Technologies of the Peter the Great St. Petersburg Polytechnic University. He received his diploma and Ph.D. degrees at the Peter the Great St. Petersburg Polytechnic University. His experience includes mathematical modeling of thermal, metallurgical, and mechanical processes in fusion welding.

Nasim Bakir received his diploma from the Aleppo University in the faculty of Mechanical Engineering (material science department). After his study, he was a lecturer at Aleppo University for the topic Finite Elements Method (2008-2010). Following, he was a guest scientist at the Berlin Institute of Technology in the department surface and joining technology (2010-2013). Since 2013, he is a researcher at the Federal Institute for Materials Research and Testing (BAM) in Berlin. He focuses on laser beam welding, hybrid laser arc welding, simulation of beam welding processes, and hot cracking phenomena.

Xiangmeng Meng, born in 1990 in Dezhou, China, received his doctor degree in the field of Material Science and Engineering from Shandong University at 2017. Currently, he is working as a post-doc researcher in the department of "Welding Technology" in the BAM Federal Institute for Materials Research and Testing in Berlin, Germany. His research topics focus on the process development and numerical simulation of arc welding and laser welding.

Dr.-Ing. Marcel Bachmann, born 1984 in Berlin, is with the BAM Federal Institute for Materials Research and Testing in Berlin, Germany in the department "Welding Technology" since 2009 where he is leading the working group "Welding Simulation." $\mathrm{He}$ received his diploma from the Berlin Institute of Technology in Engineering Science and his Ph.D. for numerical investigations of electromagnetically assisted high power laser beam welding processes. Currently, he is working on several projects involving numerical simulations in welding processes.

Dr.-Ing. Andrey Gumenyuk is the head of the working group "Laser beam welding processes" at the BAM Federal Institute for Materials Research and Testing in Berlin, Germany in the department "Welding Technology." He received his Ph.D. from the Technical University (RWTH) Aachen in Mechanical Engineering. The focus of his work is high-power laser and laser-arc hybrid welding technologies.

Professor Dr.-Ing. Michael Rethmeier is with the BAM Federal Institute for Materials Research and Testing. He is the head of the division "Welding Technology". He is also heading the "Chair of Joining Technology" at the Institute of Machine Tools and Factory Management, Berlin Institute of Technology and division director of "Joining and Coating Technology" at the Fraunhofer Institute for Production Systems and Design Technology. Present research topics include among others innovative arc welding processes, high power laser beam welding, and numerical simulations in various welding processes. 